\section{(6) OPEN ACCESS}

\title{
Normative data for flow cytometry immunophenotyping of benign lymph nodes sampled by surgical biopsy
}

\author{
Gregory David Scott, Susan K Atwater, Dita A Gratzinger
}

\begin{abstract}
- Additional material is published online only. To view please visit the journal online (http://dx.doi.org/10.1136/ jclinpath-2017-204687)
\end{abstract}

Department of Pathology, Stanford Hospital and Clinics, Stanford, California, USA

\section{Correspondence to} Dr Dita A Gratzinger, Department of Pathology, Stanford University School of Medicine, Stanford, CA 943052200, USA; ditag@stanford.edu

Received 19 July 2017 Revised 7 August 2017 Accepted 13 August 2017 Published Online First 15 September 2017
Check for updates

To cite: $S$ cott GD,

Atwater SK, Gratzinger DA. J Clin Pathol

2018:71:174-179

\begin{abstract}
Aims To create clinically relevant normative flow cytometry data for understudied benign lymph nodes and characterise outliers.

Methods Clinical, histological and flow cytometry data were collected and distributions summarised for 380 benign lymph node excisional biopsies. Outliers for kappa:lambda light chain ratio, CD10:CD19 coexpression, CD5:CD19 coexpression, CD4:CD8 ratios and CD7 loss were summarised for histological pattern, concomitant diseases and follow-up course.

Results We generated the largest data set of benign lymph node immunophenotypes by an order of magnitude. B and T cell antigen outliers often had background immunosuppression or inflammatory disease but did not subsequently develop lymphoma.

Conclusions Diagnostic immunophenotyping data from benign lymph nodes provide normative ranges for clinical use. Outliers raising suspicion for B or T cell lymphoma are not infrequent ( $26 \%$ of benign lymph nodes). Caution is indicated when interpreting outliers in the absence of excisional biopsy or clinical history, particularly in patients with concomitant immunosuppression or inflammatory disease.
\end{abstract}

\section{INTRODUCTION}

Flow cytometry immunophenotyping is a routine component of lymphoma diagnosis. Existing normative data for lymph node biopsies are based on small studies, many of which report a minority of flow gates used in routine diagnostics and were performed outside the clinical setting. Understanding the distribution of benign lymph node flow immunophenotypes is critical to prevent overdiagnosis of lymphoma, avoid unnecessary follow-up procedures and inform emerging research into automated gating.

We report the largest data set available on the distributions of clinically suspicious and ultimately benign lymph nodes, and detail immunophenotype outliers that raise suspicion for lymphoma.

\section{METHODS}

The study was approved by the Stanford University Institutional Review Board. Data included 380 excised lymph nodes with paired flow cytometry and a benign final diagnosis. Samples were processed per routine institutional protocol with 30000 events collected, and gating was performed for lymphocyte and large cell populations. The lymphocyte gate contains the CD45 + cluster with low forward scatter and low side scatter, and the large cell gate includes the CD45+ cluster with higher forward scatter and/or side scatter (online supplementary figure 1 ). Thresholds were set using isotype-matched fluorophore controls, and data were reported as \% events above the threshold. Event data were analysed using RStudio (RStudio, available at http://www.rstudio.com) and reported for the following antigens/combinations: CD2, CD3, CD4, CD5, CD7, CD8, CD10, CD16, CD19, CD20, CD22, CD23, FMC7, kappa, lambda, CD56, CD57, CD10+/CD19+, CD5+/CD19+, CD3+/ $\mathrm{CD} 56+, \mathrm{CD} 3+/ \mathrm{CD} 57+, \mathrm{CD} 3+/ \mathrm{CD} 16+, \mathrm{CD} 3-/$ $\mathrm{CD} 56+, \mathrm{CD} 3-/ \mathrm{CD} 16+$ and $\mathrm{CD} 3-/ \mathrm{CD} 57+. \mathrm{T}$ cell antigen events normalised to CD3 levels are not reported for the large cell gate given known $\operatorname{dim}$ CD4 and CD56 expression on monocytes and aggregation of monocytes and $\mathrm{T}$ cells in the large cell gate. ${ }^{1}$ CD7 loss is estimated as percentage $\mathrm{CD} 2+$ minus CD7 + events and includes both $\mathrm{T}$ and natural killer (NK) cells, although $\mathrm{T}$ cells represent the majority of events. Immunophenotypic outliers were defined for antigen combinations (CD10/19+, CD5/19+, CD7 loss) per usual as $>1.5$ times the IQR above the third quartile, and for kappa:lambda light chain ratio as $>3: 1$ or $<1: 1$, and CD4:CD8 ratio as $<1: 1$ or $>10: 1$. For outliers, medical records were evaluated for subsequent lymphoma, lymphoproliferative disorders, prior malignancy, underlying immunosuppression (including solid/ marrow transplant, chemotherapy, HIV, hypocomplementaemia, aplastic anaemia), autoimmune disease (including Graves' disease, lupus erythematosus, Raynaud's disease, psoriasis/arthritis, Hashimoto's thyroiditis, autoimmune hepatitis, Sjogren's syndrome) or inflammatory conditions (including sarcoidosis, Kawasaki's disease, ulcerative colitis, atopy). Group differences were evaluated by Mann-Whitney-Wilcoxon statistical test.

\section{RESULTS}

The cohort gender mix was $51.1 \%$ female and 48.9\% male, and age distribution slightly skewed towards older patients (median $=33.5$ years old, range 8 months -82 years); nevertheless, paediatric patients are represented, with 129 patients under age 18. A median of $90 \%$ of events fall in the lymphocyte gate, and $5 \%$ in the large cell gate. In the lymphocyte gate, a median of $60 \%$ of events are CD3+ (T cells) and 32\% are CD19+ (B cells) (figures 1-2, tables 1-2), and the opposite distribution of CD19+ (median $=68 \%)$ and 
Lymphocyte Gate

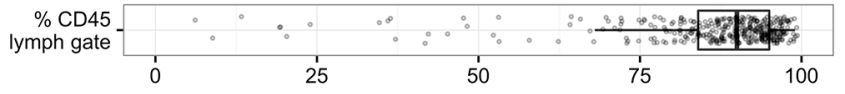

B-Cell Related Antigens (Lymphocyte Gate)

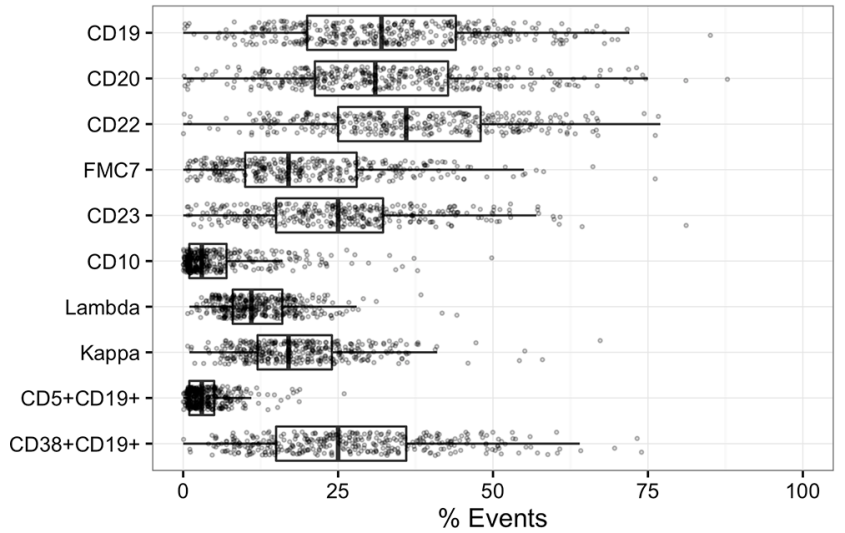

Large Cell Gate

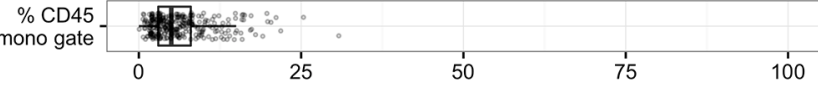

B-Cell Related Antigens (Large Cell Gate)

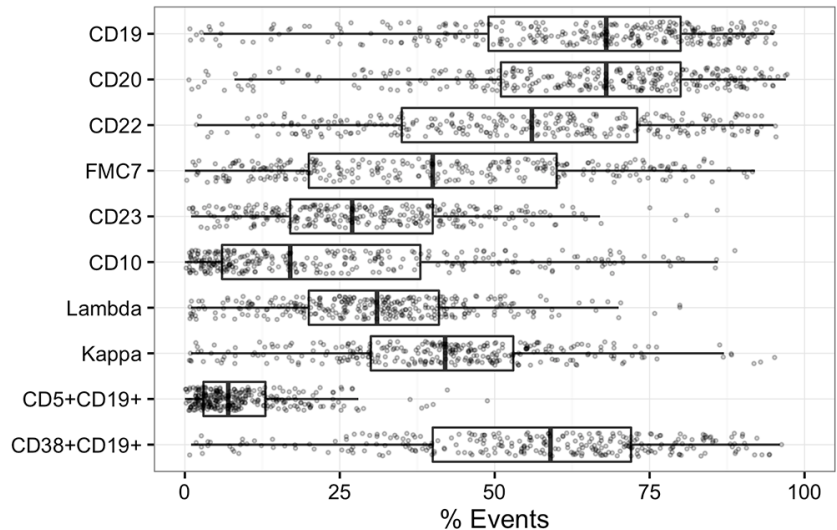

Figure 1 Event percentages for B cell-related antigens in the lymphocyte gate (left) and large cell gate (right) are plotted as jittered dotplots with overlying box-and-whisker plots demonstrating data median and quartiles.

$\mathrm{CD} 3+($ median $=27 \%)$ events is present in the large cell gate, consistent with enrichment for larger germinal centre B cells (figure 1-2, tables 1-2). Clinical characteristics and median flow gate events were similar to previous studies of excised benign lymph nodes. ${ }^{2-9}$ Combined lymphocyte and large cell gate data are presented in online supplementary table 1.

B lineage-related antigens (CD10+/CD19+, CD5+/CD19+, CD22, CD23, FMC-7) covary with percent CD19+ events, and kappa:lambda light chain ratios fall mostly within the normal range of $1: 1$ to $3: 1$ (table 1). Twenty-three kappa:lambda outliers (outside 1:1-3:1 ratio) were identified, 5 cases $(1.3 \%)$ in the lymphocyte gate and 17 cases $(4.4 \%)$ in the large cell gate (tables 3-4). These biopsies exhibited reactive follicular hyperplasia, with three cases notable for granulomatous histology. Outliers in the lymphocyte gate exhibited significantly increased
CD10+/CD19+ events (outlier median $=36 \%$, non-outlier median $=9.5 \%, \mathrm{p}<0.01$ ), and four of five patients were immunosuppressed (eg, status postorgan transplant) or had an inflammatory/autoimmune (eg, lupus erythematosus) condition. In contrast, outliers in the large cell gate did not have increased CD10+/CD19+ events, and 8 of 17 patients had history of immunosuppression or an inflammatory/autoimmune condition.

Median CD10+/CD19+ B cells events were low (9.8\%) in the lymphocyte gate and $29.8 \%$ in the large cell gate, consistent with germinal centre enrichment, and the distribution is right-skewed with upper quartiles $>22 \%$ and $>55 \%$ in the lymphocyte and large cell gates, respectively (table 1). Outliers in the lymphocyte gate represent $5.7 \%(n=21)$ of cases and in the large cell gate $1.6 \%(n=5)$ of cases (tables $3-4)$. The top 10 CD10+/CD19+ outliers (five each for lymphocyte and large

\section{Lymphocyte Gate}

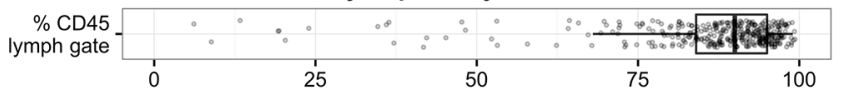

T/NK-Cell Related Antigens (Lymphocyte Gate)
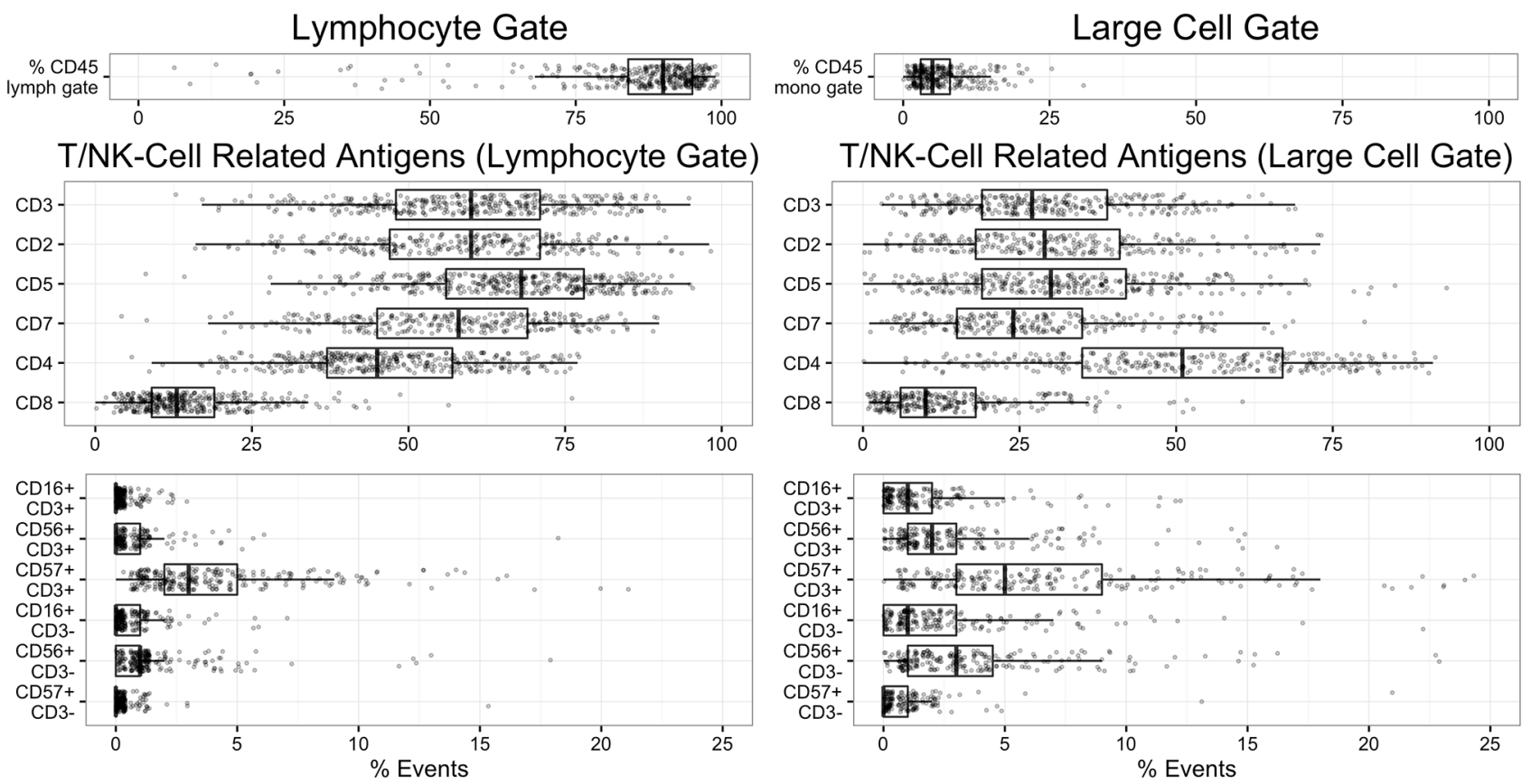

T/NK-Cell Related Antigens (Large Cell Gate)
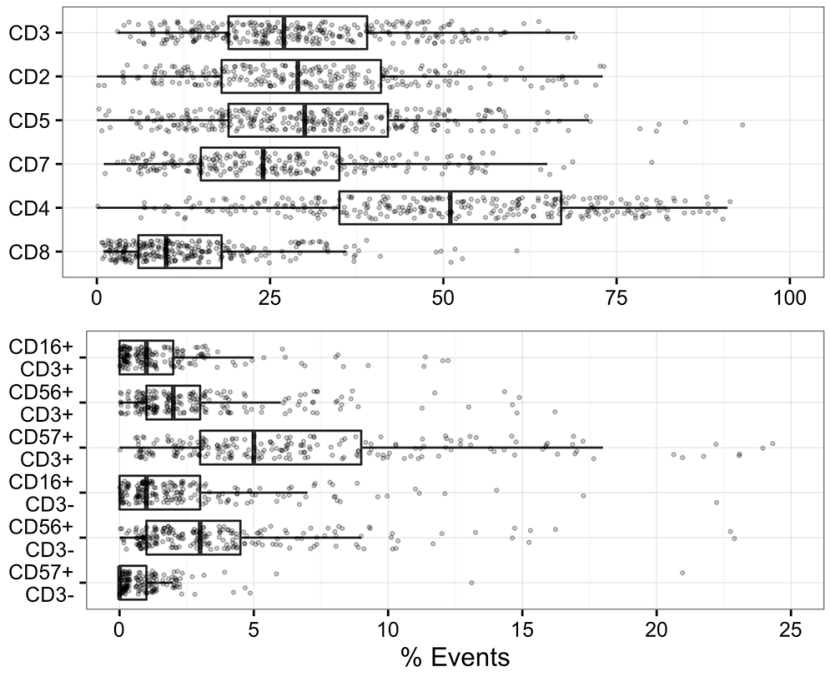

Figure 2 Event percentages for T cell-related/NK cell-related antigens in the lymphocyte gate (left) and large cell gate (right) are plotted as jittered dotplots with overlying box-and-whisker plots demonstrating data median and quartiles. NK, natural killer. 
Table 1 Lymphocyte gate: normative distribution of B cell-related, T cell-related and NK cell-related epitopes

\begin{tabular}{|c|c|c|c|c|c|c|}
\hline & Median & $(\mathrm{Q1}, \mathrm{Q3})$ & $(5 \%, 95 \%)$ & $\mathrm{N}$ & $\%$ CD19 & $(\mathrm{Q1}, \mathrm{Q3})$ \\
\hline$\%$ CD45 & 90 & $(84,95)$ & $(55,97)$ & 368 & & \\
\hline CD3:CD19 & 1.8 & $(1.0,3.1)$ & $(0.5,6.9)$ & 359 & & \\
\hline \multicolumn{7}{|l|}{ B cell antigens } \\
\hline CD19 & 32 & $(20,44)$ & $(11,60)$ & 378 & & \\
\hline CD20 & 31 & $(22,43)$ & $(11,61)$ & 371 & 100 & $(94.1,104)$ \\
\hline CD22 & 36 & $(25,48)$ & $(13,62)$ & 331 & 110 & $(101.1,125.7)$ \\
\hline FMC7 & 17 & $(10,28)$ & $(3,43)$ & 349 & 57.1 & $(38.5,77.7)$ \\
\hline CD23 & 25 & $(15,33)$ & $(5,50)$ & 349 & 77.8 & $(57.7,96.6)$ \\
\hline CD10 & 3 & $(1,7)$ & $(0,20)$ & 371 & 9.8 & $(5,22.7)$ \\
\hline CD38+CD19+ & 25 & $(15,36)$ & $(7,51)$ & 361 & 83.8 & $(69.6,93.3)$ \\
\hline CD5+CD19+ & 3 & $(1,5)$ & $(0,10)$ & 373 & 8.8 & $(5,14.7)$ \\
\hline Kappa+ & 17 & $(12,24)$ & $(7,35)$ & 371 & 55.6 & $(50,60.4)$ \\
\hline Lambda+ & 11 & $(8,16)$ & $(5,23)$ & 370 & 36.8 & $(32.8,40.5)$ \\
\hline Kappa:lambda & 1.5 & $(1.3,1.7)$ & $(1.1,2.2)$ & 370 & & \\
\hline $\mathrm{T}$ cell antigens & & & & & $\% \mathrm{CD} 3$ & \\
\hline CD3 & 60 & $(48,71)$ & $(31,84)$ & 364 & & \\
\hline CD4 & 45 & $(37,57)$ & $(23,70)$ & 365 & 80.3 & $(72.3,86.7)$ \\
\hline CD8 & 13 & $(9,19)$ & $(4,31)$ & 365 & 22.5 & $(16.3,30.7)$ \\
\hline CD5 & 64 & $(52,75)$ & $(36,86)$ & 373 & 105.2 & $(100,111.4)$ \\
\hline $\mathrm{CD} 2$ & 60 & $(47,71)$ & $(29,82)$ & 281 & 98.5 & $(95.6,101.3)$ \\
\hline CD7 & 58 & $(44,69)$ & $(31,80)$ & 282 & 95.8 & $(91.7,98.9)$ \\
\hline $\mathrm{CD} 16+\mathrm{CD} 3+$ & 0 & $(0,0)$ & $(0,1)$ & 268 & 0 & $(0,0)$ \\
\hline $\mathrm{CD} 56+\mathrm{CD} 3+$ & 0 & $(0,1)$ & $(0,2)$ & 277 & 0 & $(0,1.3)$ \\
\hline $\mathrm{CD} 57+\mathrm{CD} 3+$ & 3 & $(2,5)$ & $(1,10.8)$ & 265 & 5 & $(2.6,10.3)$ \\
\hline CD4:CD8 & 3.5 & $(2.4,5.3)$ & $(1.1,10.7)$ & 364 & & \\
\hline CD7-negative T/NK (\% CD2) & $2.7 \%$ & $(-1.2,6.5)$ & $(-10,14)$ & 279 & & \\
\hline \multicolumn{7}{|l|}{ NK cell antigens } \\
\hline CD16+CD3- & 0 & $(0,0)$ & $(0,1)$ & 267 & & \\
\hline $\mathrm{CD} 56+\mathrm{CD} 3-$ & 1 & $(0,1)$ & $(0,4)$ & 266 & & \\
\hline CD57+CD3- & 0 & $(0,0)$ & $(0,1)$ & 265 & & \\
\hline
\end{tabular}

NK, natural killer.

cell gates, one shared between groups) showed reactive follicular hyperplasia, with three cases additionally showing follicle lysis and two cases suggestive of HIV lymphadenitis. Eight of nine patients were either immunosuppressed or had an inflammatory/ autoimmune condition.

Median CD5+/CD19+ Bcell percentages were low (8.8\%) in the lymphocyte gate and $11.8 \%$ in the large cell gate, with a right-skewed distribution showing an upper quartile $>14.7 \%$ and $>21.6 \%$ of events in the lymphocyte and large cells gate, respectively (table 1). Outliers in the lymphocyte and large cell gates represent $7.6 \%(n=28)$ and $4.7 \%(n=14)$ of cases, respectively (tables 3-4). The top 10 CD10+/CD19+ outliers (five each for lymphocyte and large cell gates, one shared between groups) showed mostly reactive follicular hyperplasia, and kappa:lambda light chain ratios were within normal range. CD5+/CD19+ outliers in the lymphocyte gate were significantly younger (outlier mean $=13$ years, non-outlier mean $=33.9$ years, $\mathrm{p}<0.05$ ) and had increased CD5 +/CD19+ events in the large cell gate (outlier median $=40 \%$, non-outlier median $=11 \%$, $\mathrm{p}<0.01)$. In contrast, outliers in the large cell gate were not significantly younger than the overall cohort (median age $=31.4$ years old) and did not have increased CD5+/CD19+ events in the lymphocyte gate (median CD $5+/ \mathrm{CD} 19+=31 \%$ ). Four of nine outliers (44\%) were immunosuppressed or had inflammatory/autoimmune diseases.

The distribution of FMC-7 and CD23 is broad in both lymphocyte and large cell gates (table 1), with FMC7 correlated to its epitope CD20 and CD22 slightly higher than CD19. CD19+ events are generally CD38+, more so in the large cell gate $(\mathrm{p}<0.01$ vs lymphocyte gate). Percent CD19+/ CD38 + events show a moderate positive correlation with CD10 + events (lymphocyte gate, $\mathrm{r}=0.29, \mathrm{n}=353, \mathrm{p}<0.001$ ).

T lineage epitope (CD3, CD2, CD5 and CD7) distributions are reported for both the lymphocyte and large cell gates (figure 2, table 2), and the large cell gate is not further assessed due to non-specific binding (discussed above). Lymphocyte gated CD2, CD5 and CD7 track closely with CD3, and ratios for CD4:CD8 have a median of 3.5:1 as expected. CD4:CD8 outliers are frequent ( $8 \%$ of cases, $n=32$ ) (tables $3-4)$, and the top 10 CD4:CD8 outliers above 10:1 and below 1:1 reflect overall group demographics, and there is no increased CD7 loss or aberrant natural killer/T (NKT) phenotype (CD56/ CD3 or CD57/CD3). Several distinct diagnoses are represented among <1:1 CD4:CD8 outliers, including histiocytic necrotising lymphadenitis (Kikuchi lymphadenitis), Castleman disease, granulomatous lymphadenitis and HIV lymphadenitis, whereas the $>10: 1$ CD4:CD8 outlier group is enriched for immunocompromised/post-transplant status (70\% of patients).

In terms of estimated CD7 loss, the cohort has a median of $2.7 \% \mathrm{CD} 2+/ \mathrm{CD} 7-$ events in the lymphocyte gate, with the upper quartile $>6.5 \%$ CD2+/CD7- events (table 2). CD7 loss outliers (tables 3-4) represent 6.8\% $(n=19)$ of cases for the lymphocyte gate and the top 10 outliers did not contain aberrant CD4:CD8 ratios or aberrant NKT phenotype 
Table 2 Large cell gate: normative distribution of B cell-related, T cell-related and NK cell-related epitopes

\begin{tabular}{|c|c|c|c|c|c|c|}
\hline & Median & $(\mathrm{Q1}, \mathrm{Q3})$ & $(5 \%, 95 \%)$ & $\mathrm{N}$ & $\%$ CD19 & $(\mathrm{Q1}, \mathrm{Q3})$ \\
\hline$\%$ CD45 & 5 & $(3,8)$ & $(2,16)$ & 299 & & \\
\hline CD3:CD19 & 0.4 & $(0.2,0.7)$ & $(0.1,1.6)$ & 289 & & \\
\hline \multicolumn{7}{|l|}{ B cell antigens } \\
\hline CD19 & 68 & $(49,80)$ & $(14,91)$ & 302 & & \\
\hline CD20 & 68 & $(51,80)$ & $(11,91)$ & 296 & 97.8 & $(92.7,105.5)$ \\
\hline CD22 & 56 & $(35,73)$ & $(16,89)$ & 274 & 86.3 & $(69,97.7)$ \\
\hline CD10 & 17 & $(6,38)$ & $(2,69)$ & 296 & 29.8 & $(13.7,55.8)$ \\
\hline CD38+CD19+ & 59 & $(40,72)$ & $(9,89)$ & 289 & 92.6 & $(82.3,98.1)$ \\
\hline CD5+CD19+ & 7 & $(3,13)$ & $(1,25)$ & 296 & 11.8 & $(6.3,21.6)$ \\
\hline Kappa+ & 42 & $(30,53)$ & $(7,72)$ & 299 & 64 & $(53.4,77.5)$ \\
\hline Lambda+ & 31 & $(20,41)$ & $(5,56)$ & 300 & 46.6 & $(38.2,60.1)$ \\
\hline CD8 & 10 & $(6,18)$ & $(2,35)$ & 288 & & \\
\hline CD5 & 20 & $(11,30)$ & $(5,52)$ & 296 & & \\
\hline CD2 & 30 & $(18,41)$ & $(8,63)$ & 238 & & \\
\hline $\mathrm{CD} 7$ & 24 & $(15,35)$ & $(6,54)$ & 239 & & \\
\hline $\mathrm{CD} 16+\mathrm{CD} 3+$ & 1 & $(0,2)$ & $(0,6)$ & 229 & & \\
\hline $\mathrm{CD} 56+\mathrm{CD} 3+$ & 2 & $(1,3)$ & $(0,8)$ & 231 & & \\
\hline $\mathrm{CD} 57+\mathrm{CD} 3+$ & 6 & $(3,10)$ & $(1,23.6)$ & 229 & & \\
\hline CD4:CD8 & 4.5 & $(3,7.2)$ & $(1.4,14.5)$ & 288 & & \\
\hline \multicolumn{7}{|l|}{ NK cell antigens } \\
\hline CD16+CD3- & 1 & $(0,3)$ & $(0,10)$ & 231 & & \\
\hline
\end{tabular}

NK, natural killer.

$(\mathrm{CD} 56+\mathrm{CD} 3+\operatorname{median}=0.5 \%, \mathrm{CD} 57+\mathrm{CD} 3+\operatorname{median}=3 \%)$. CD7 loss outliers typically exhibited follicular hyperplasia $(60 \%$ of cases).

Outliers mentioned above (kappa:lambda, CD10/CD19, CD5/CD19, CD4:CD8 or CD7 loss) represented 98 cases (26\% of all cases, online supplementary figure 2). Among outlier cases, $76 \%, 20 \%$ and $4 \%$ of cases had one, two and three outliers, respectively. No patterns of covariance among outlier types were identified and the proportions of outlier types were 17\% kappa:lambda, 19\% CD10/CD19, 26\% CD5/ CD19, 26\% CD4:CD10 and 6\%CD7 loss. Outliers did not subsequently develop lymphoma, and group gender and age were similar to the overall cohort except for younger age in CD5+/CD19+ outliers.

CD16+/CD3 - NK cells, CD56+/CD3 - NK cells, CD57+/CD3 - NK cells, CD16+/CD3+ NKT cells, CD56+/ CD3 + NKT cells and CD57+/CD3 + (cytotoxic and/or follicular helper) $\mathrm{T}$ cells showed low abundance (median $=1 \%$, table 2), and negligible events express mature markers (CD57+/ CD3-, median $0 \%$ and CD16+/CD3-, median 0\%), in line with previous data. ${ }^{10} 11$

\section{DISCUSSION}

We present the largest normative data set of common diagnostic flow immunophenotypic markers in benign lymph nodes and summarise clinical data in outlier groups.

Flow immunophenotypic assessment for B cell lymphoma relies predominantly on coexpression of CD5 or CD10 and light chain ratios. Previously reported mean/maxima for CD10 and CD5-positive B lymphocytes in benign lymph nodes were $16 \% / 50 \%$ for CD10 and 15\%/30\% for CD5. ${ }^{12} 13$ A striking 5.1\% and $6.9 \%$ of cases in the current study exceeded the previous maxima for $\mathrm{CD} 10+$ and CD $5+\mathrm{CD} 19+$, respectively. This is a potential pitfall since CD10 and CD5-positive B lymphocytes are conceptualised as minority populations in benign lymph nodes, and neoplasms of mature B cells are classified using aberrant CD10 and CD5 expression patterns. ${ }^{14} 15$ In the current study top outliers of CD10 and CD5 did not develop B cell lymphoma on subsequent (median $\sim 4$ year) follow-up.

Light chain restriction is another diagnostic clue for B cell lymphoma, although skewed light chain ratios have been reported in normal childhood tonsils, Castleman disease and reactive follicular hyperplasia. ${ }^{14}$ In the current study, aberrant kappa:lambda light chain ratios were present in $1.3 \%$ and $5.7 \%$ of cases in the lymphocyte and large cell gate, respectively, and were mostly attributed to germinal centre B cells, consistent with enrichment in the large cell gate and increased CD10+/CD19+ events. Previous reports of reactive benign lymph nodes showed $\sim 1 \%$ cases with clonal light chain-restricted $\mathrm{CD} 10+$ germinalcentre B cells representing at least $20 \%$ of total B cells. ${ }^{16}$ The current study similarly shows skewed kappa:lambda light chain ratios as a potential diagnostic pitfall occurring in a significant number of benign lymph nodes that do not subsequently develop lymphoma.

We assessed $\mathrm{T}$ cell immunophenotypic aberrancies that may be seen in $\mathrm{T}$ cell lymphoma. Loss and underexpression of CD7 
Table 3 Immunophenotype outliers with benign diagnosis and negative for lymphoma on follow-up: demographics and related markers

\begin{tabular}{|c|c|c|c|c|c|c|c|}
\hline Kappa:lambda ratio $>3: 1$ or $<1: 1$ & $\mathrm{~N}$ & $M: F$ & Age & $K: L(L G)$ & $\mathrm{K}: \mathrm{L}(\mathrm{LCG})$ & CD10 (LG) & CD10 (LCG) \\
\hline $\begin{array}{l}\text { Lymphocyte } K: L<1: 1 \\
\text { Gate } K: L>3: 1\end{array}$ & 5 & $2: 3$ & $\begin{array}{l}38.6 \\
(3-63)\end{array}$ & $\begin{array}{l}0.7(0.4-0.9) \\
3.1\end{array}$ & $1(0.3-1)$ No data & $36(9-71) \dagger$ & $43(16-64)$ \\
\hline $\begin{array}{l}\text { Large cell } K: L<1: 1 \\
\text { Gate } K: L>3: 1\end{array}$ & 17 & $7: 9$ & $\begin{array}{l}25.1 \\
(3-76)\end{array}$ & $\begin{array}{l}1.1(0.4-1.5) \\
1.6(1.5-2.3)\end{array}$ & $\begin{array}{l}0.9(0.3-0.9) \\
3.8(3.1-5.5)\end{array}$ & $11(0-50)$ & $36(5-86)$ \\
\hline CD10/19 outliers* & $\mathrm{N}$ & $M: F$ & Age & $K: L(L G)$ & $\mathrm{K}: \mathrm{L}(\mathrm{LCG})$ & CD10 (LG) & CD10 (LCG) \\
\hline Lymphocyte gate & 5 & $3: 2$ & $\begin{array}{l}39.6 \\
(3-68)\end{array}$ & $1.8(1.5-3.1)$ & $1.4(1.3-2.6)$ & $74(69-90)$ & $84(84-94)$ \\
\hline Large cell gate & 5 & 4:1 & $\begin{array}{l}29.5 \\
(5-68)\end{array}$ & $1.6(1.0-1.7)$ & $1.4(1-2.6)$ & $60(14-69)$ & 94 (88-97) \\
\hline CD5/19 outliers* & $\mathrm{N}$ & $M: F$ & Age & $\mathrm{K}: \mathrm{L}(\mathrm{LG})$ & $\mathrm{K}: \mathrm{L}(\mathrm{LCG})$ & CD5 (LG) & CD5 (LCG) \\
\hline Lymphocyte gate & 5 & $4: 1$ & $\begin{array}{l}13 \dagger \\
(2-42)\end{array}$ & $1.5(1.2-1.8)$ & $1.1(0.9-1.2)$ & $41(40-57)$ & $40(27-65) \dagger$ \\
\hline Large cell gate & 5 & $3: 2$ & $\begin{array}{l}31.4 \\
(2-70)\end{array}$ & $1.2(1.1-1.4)$ & $1.2(1.1-1.4)$ & $31(0-57)$ & $65(57-100)$ \\
\hline CD4:CD8 >10:1/<1:1 & $\mathrm{N}$ & $M: F$ & Age & $\mathrm{CD} 4: \mathrm{CD} 8$ & CD7 loss & $\mathrm{CD} 56+\mathrm{CD} 3+$ & $\mathrm{CD} 57+\mathrm{CD} 3+$ \\
\hline $\begin{array}{l}\text { CD4:CD8 <1:1 } \\
\text { (lowest 10) }\end{array}$ & 10 & $7: 3$ & $\begin{array}{l}31 \\
(3-68)\end{array}$ & $0.7(0.3-0.9)$ & $-1.5(-13$ to 29$)$ & $0(0-7)$ & $1(0-25)$ \\
\hline $\begin{array}{l}\text { CD4:CD8 >10:1 } \\
\text { (top 10) }\end{array}$ & 10 & $5: 5$ & $\begin{array}{l}30.5 \\
(2-74)\end{array}$ & $17.1(14.6-36)$ & $0(-4$ to 12$)$ & $0(0-0)$ & $3(1-7)$ \\
\hline \multirow[t]{2}{*}{ CD7 loss outliers* } & $\mathrm{N}$ & $\mathrm{M}: \mathrm{F}$ & Age & CD4:CD8 & CD7 loss & $\mathrm{CD} 56+\mathrm{CD} 3+$ & $\mathrm{CD} 57+C D 3+$ \\
\hline & 10 & $4: 6$ & $\begin{array}{l}36.5 \\
(5-68)\end{array}$ & $3.5(0.7-6.8)$ & $28(16-80)$ & $0.5(0-4)$ & $4(1-16)$ \\
\hline
\end{tabular}

${ }^{*}$ Outlier defined as greater than 1.5 times the IQR above the third quartile. One overlapping case between kappa:lambda and CD10, one between kappa:lambda and CD5, one between kappa:lambda LG and LCG.

tSignificant difference compared with all non-outliers, $\mathrm{p}<0.01$ (Mann-Whitney-Wilcoxon test).

K:L, kappa:lambda; LCG, large cell gate; LG, lymphocyte gate; M:F, male-to-female ratio; N, sample size.

is associated with roughly $54 \%$ of $\mathrm{T}$ cell lymphomas. ${ }^{17}$ In the current study, loss of CD7 on CD2+ events (T and NK cells) was usually low (2.7\% of CD2+ events), but a surprising 39 cases (13.9\% of cases) showed over 10\% CD7 loss and 9 cases $(3.2 \%$ of cases) had over 20\% loss. NK cell epitopes (CD16+, CD56+, CD57+) were low with $0 \%$ and $1 \%$ medians, so CD7 loss was attributable to the $\mathrm{T}$ cell population. A previous study pooling non-T cell malignancy lymph nodes (benign, reactive, B cell

Table 4 Immunophenotype outliers with benign diagnosis and negative for lymphoma on follow-up: histological and clinical features

\begin{tabular}{|c|c|c|c|c|c|c|c|c|c|c|c|}
\hline & \multicolumn{7}{|c|}{ Reactive pattern/diagnosis } & \multirow[b]{2}{*}{ IS TRA } & \multirow[b]{2}{*}{ AI INF } & \multirow[b]{2}{*}{ F/U (years) } & \multirow{2}{*}{$\begin{array}{l}\text { F/U } \\
\text { LYM }\end{array}$} \\
\hline & Neg & RFH & $\mathrm{FL}$ & PTGC & $\mathrm{PH}$ & DL & Other & & & & \\
\hline \multicolumn{12}{|l|}{$\begin{array}{l}\text { Kappa:lambda ratio } \\
>3: 1 \text { or }<1: 1\end{array}$} \\
\hline $\begin{array}{l}\text { Lymphocyte } K: L<1: 1 \\
\text { Gate } K: L>3: 1\end{array}$ & & 4 & 1 & 1 & 1 & & $S D(n=1)$ & 2 & 2 & $4.2(1-7)$ & - \\
\hline $\begin{array}{l}\text { Large cell } K: L<1: 1 \\
\text { Gate } K: L>3: 1\end{array}$ & 1 & 11 & & 1 & & 1 & $\begin{array}{l}\text { AH }(n=1), K D(n=1), C D(n=1), \\
\text { GL/IFXN }(n=2)\end{array}$ & 3 & 5 & $\begin{array}{l}2.8(1 \text { month-12 } \\
\text { years) }\end{array}$ & - \\
\hline \multicolumn{12}{|l|}{ CD10/19 outliers* } \\
\hline Lymphocyte gate & & 5 & 2 & & & & HIV-LA ( $n=2)$ & 4 & 1 & $3.6(2-6)$ & - \\
\hline Large cell gate & & 5 & 1 & & 1 & & HIV-LA ( $n=1)$ & 3 & 2 & $4.8(2-7)$ & - \\
\hline \multicolumn{12}{|l|}{ CD5/19 outliers* } \\
\hline Lymphocyte gate & & 4 & & 1 & & & & 2 & & $4.2(1-9)$ & - \\
\hline Large cell gate & 2 & 3 & & & & & $S D(n=1)$ & 1 & 2 & $4(1-8)$ & - \\
\hline \multicolumn{12}{|l|}{ CD4:CD8 >10:1/<1:1 } \\
\hline $\begin{array}{l}\text { CD4:CD8 <1:1 } \\
\text { (lowest 10) }\end{array}$ & 3 & 2 & 2 & & & 1 & $\begin{array}{l}\mathrm{KD}(n=2), C D(n=1), G L(n=1) \\
\text { HIV-LA }(n=1)\end{array}$ & 5 & 4 & $\begin{array}{l}3.3(2 \text { months }-9 \\
\text { years) }\end{array}$ & - \\
\hline $\begin{array}{l}\text { CD4:CD8 >10:1 } \\
\text { (top 10) }\end{array}$ & 2 & 6 & & & & & $S D(n=1)$ & 7 & 2 & $4.6(1-8)$ & - \\
\hline \multicolumn{12}{|l|}{ CD7 loss outliers* } \\
\hline & 1 & 6 & 1 & & 1 & 2 & LG $(n=1)$, HIV-LA $(n=1)$ & 5 & 4 & $\begin{array}{l}2.5 \text { ( } 4 \text { months-7 } \\
\text { years) }\end{array}$ & - \\
\hline
\end{tabular}

*Outlier defined as greater than 1.5 times the IQR above the third quartile. One overlapping case between kappa:lambda and CD10, one between kappa:lambda and CD5, one between kappa:lambda lymphocyte gate (LG) and large cell gate (LCG).

Clinical acronyms: AI INF, autoimmune or inflammatory disease; F/U LYM, subsequent lymphoma on follow-up; F/U (years), duration of follow-up in years; INFL, inflammatory condition; IS TRA, immunosuppressed or (solid organ or marrow) transplant.

Diagnosis/Pattern acronyms: AH, angiomyomatous hamartoma; $C D$, Castleman disease; DL, dermatopathic lymphadenopathy; $F L$, follicular lysis; $G L$, granulomatous lymphadenitis; HIV-LA, HIV lymphadenitis; IFXN, infectious lymphadenitis; KD, Kikuchi disease; LG, lipogranulomatosis; Neg, negative; PH, paracortical hyperplasia; PTGC, progressive transformation of germinal centres; $\mathrm{RFH}$, reactive follicular hyperplasia; $\mathrm{SD}$, sarcoidosis. 
lymphoma) showed similar low consistent loss of $\mathrm{T}$ cell epitopes, including occasional CD7 loss in greater than $20 \%$ of T cells. ${ }^{17}$ Our 10 cases with greatest estimated CD7 loss did not develop T cell lymphoma or T cell rich B lineage lymphomas (eg, Hodgkin lymphoma).

In the current study, $5.7 \%$ and $3 \%$ of CD4:CD 8 ratios were above and below the normal 1:1-10:1 range. ${ }^{18}$ Aberrant CD7 or CD4:CD8 ratios of unknown significance have been reported in a variety of settings ranging from infection to transient effects of smoking, ${ }^{19} 20$ and in patients with HIV likely reflect absolute CD4 T cell deficiency. CD4:CD8 outliers within our cohort highlighted several benign entities, including histiocytic necrotising lymphadenitis (Kikuchi lymphadenitis), granulomatous lymphadenitis, HIV infection and dermatopathic lymphadenopathy.

Flow cytometry provides important ancillary information in the diagnosis of lymphoma, particularly when clinical or histology findings are limited, equivocal or mimic malignancy. It is critical to recognise borderline cases in order to avoid misdiagnosing lymphoma, and the current study estimates one-quarter of benign nodes exhibit outlier immunophenotypes suspicious for lymphoma. This study provides a comprehensive benign data set for manual and automated diagnosis of lymphoma.

\section{Take home messages}

- Outlier flow immunophenotypes are seen in approximately $1 / 4$ of benign lymph nodes.

- Understanding of benign outliers is crucial to avoid overdiagnosis of lymphoma or unnecessary repeat studies.

- Frequent outliers involving B cells include skewed kappa:lambda ratios, and increased percent CD5:CD19 or CD10:CD19 coexpression.

- Frequent outliers involving T cells include $<1: 1$ or $>10: 1$ CD4:CD8 ratio or partial loss of CD7.

- Clinical history often reveals an autoimmune, rheumatologic or immunodeficiency condition among outliers.

\section{Handling editor Mary Frances McMullin.}

Contributors GDS and DG planned the study. GDS performed data collection, software programming and analysis. GDS, DG, and SA conducted data interpretation, critical review and drafting of the manuscript.

Competing interests None declared.

Ethics approval Stanford University Institutional Review Board.

Provenance and peer review Not commissioned; externally peer reviewed.

Data sharing statement Raw flow event data will be made available by email request at the discretion of the corresponding author.

Open Access This is an Open Access article distributed in accordance with the Creative Commons Attribution Non Commercial (CC BY-NC 4.0) license, which permits others to distribute, remix, adapt, build upon this work non-commercially, and license their derivative works on different terms, provided the original work is properly cited and the use is non-commercial. See: http://creativecommons.org/ licenses/by-nc/4.0/

(C) Article author(s) (or their employer(s) unless otherwise stated in the text of the article) 2018. All rights reserved. No commercial use is permitted unless otherwise expressly granted.

\section{REFERENCES}

1 Storek J, Dawson MA, Maloney DG. Comparison of two flow cytometric methods enumerating CD4 T cells and CD8 T cells. Cytometry 1998;33:76-82.

2 Backteman K, Andersson C, Dahlin LG, et al. Lymphocyte subpopulations in lymph nodes and peripheral blood: a comparison between patients with stable angina and acute coronary syndrome. PLoS One 2012;7:e32691.

3 Battaglia A, Ferrandina G, Buzzonetti A, et al. Lymphocyte populations in human lymph nodes. Alterations in CD4+ CD25+ T regulatory cell phenotype and T-cell receptor V $\beta$ repertoire. Immunology 2003;110:304-12.

4 Bryan CF, Eastman PJ, Conner JB, et al. Clinical utility of a lymph node normal range obtained by flow cytometry. Ann N Y Acad Sci 1993;677:404-6.

5 Gunduz E, Celebioglu M, Meltem Akay O, et al. The role of flow cytometry in the diagnosis of non- Hodgkin's lymphoma, Hodgkin's lymphoma, granulomatous inflammation and reactive lymph node specimens. J BUON Off J Balk Union Oncol 2013;18:739-45.

6 Hudnall SD, Betancourt E, Barnhart E, et al. Comparative flow immunophenotypic features of the inflammatory infiltrates of Hodgkin lymphoma and lymphoid hyperplasia. Cytometry B Clin Cytom 2008;74:1-8.

7 Kelly-Williams S, Zmijewski CM, Tomaszewski JE. Lymphocyte Subpopulations in 'Normal' Lymph Nodes Harvested From Cadavers. Lab Med 1989;20:487-90.

8 Maiese RL, Segal GH, Iturraspe JA, et al. The cell surface antigen and DNA content distribution of lymph nodes with reactive hyperplasia. Mod Pathol 1995;8:536-43.

9 Westermann CD, Hurtubise PE, Linnemann CC, et al. Comparison of histologic nodal reactive patterns, cell suspension immunophenotypic data, and HIV status. Mod Pathol 1990:3:54-60.

10 Caligiuri MA. Human natural killer cells. Blood 2008;112:461-9.

11 Gibson SE, Swerdlow SH, Felgar RE. Natural killer cell subsets and natural killer-like T-cell populations in benign and neoplastic B-cell proliferations vary based on clinicopathologic features. Hum Pathol 2011;42:679-87.

12 Almasri NM, Iturraspe JA, Braylan RC. CD10 expression in follicular lymphoma and large cell lymphoma is different from that of reactive lymph node follicles. Arch Pathol Lab Med 1998;122:539-44.

13 Youinou P, Jamin C, Lydyard PM. CD5 expression in human B-cell populations. Immunol Today 1999;20:312-6.

14 Craig FE, Foon KA. Flow cytometric immunophenotyping for hematologic neoplasms. Blood 2008;111:3941-67.

15 Szczepański T, van der Velden VH, van Dongen JJ. Flow-cytometric immunophenotyping of normal and malignant lymphocytes. Clin Chem Lab Med 2006;44:775-96

16 Kussick SJ, Kalnoski M, Braziel RM, et al. Prominent clonal B-cell populations identified by flow cytometry in histologically reactive lymphoid proliferations. Am J Clin Pathol 2004;121:464-72.

17 Jamal S, Picker LJ, Aquino DB, et al. Immunophenotypic analysis of peripheral T-cell neoplasms. A multiparameter flow cytometric approach. Am J Clin Pathol 2001;116:512-26.

18 Gorczyca W, Weisberger J, Liu Z, et al. An approach to diagnosis of T-cell lymphoproliferative disorders by flow cytometry. Cytometry 2002;50:177-90.

19 Flammiger A, Bacher U, Christopeit M, et al. Multiparameter flow cytometry in the differential diagnosis of aberrant T-cell clones of unclear significance. Leuk Lymphoma 2015;56:639-44

20 Sorigué $\mathrm{M}$, Juncà J, Marcé $\mathrm{S}$, et al. The role of T-cell phenotype and T-cell receptor rearrangement in the diagnosis of T-cell malignancies. Leuk Lymphoma 2016:57:244-6. 